\title{
CLINICAL STUDY ON FACTORS INFLUENCING WOUND DEHISCENCE IN EMERGENCY EXPLORATORY LAPAROTOMY
}

\author{
Mrinal Talukdar1, Sankamithra Gopalarathnam², Rajesh Paul³, Abdul Rahim Shaan ${ }^{4}$
}

${ }^{1}$ Assistant Professor, Department of General Surgery, Silchar Medical College and Hospital.

${ }^{2}$ Post Graduate Trainee, Department of General Surgery, Silchar Medical College and Hospital.

${ }^{3}$ Post Graduate Trainee, Department of General Surgery, Silchar Medical College and Hospital.

${ }^{4}$ Post Graduate Trainee, Department of General Surgery, Silchar Medical College and Hospital.

\section{ABSTRACT}

\section{BACKGROUND}

Wound dehiscence is a mental, financial and physical trauma to patients and has an equivalent effect on surgeon too. Wound dehiscence etches profound morbidity in a patient's life. There arises an expanding demand in the cost of care, both in terms of increased hospital stay and manpower in nursing and managing of burst wound and its complications. Thus understanding of factors contributing to dehiscence, correctable measures and precautionary steps are very much essential in day-to-day practice of all surgeons. This ignited our thoughts to conduct a study and understand wound healing and dehiscence in a better way.

\begin{abstract}
AIM
This study was made to find the factors that significantly contribute to wound dehiscence in midline emergency exploratory laparotomy.

\section{METHODS}

The study was conducted in 213 patients who underwent midline emergency exploratory laparotomy in Silchar Medical College and Hospital in Barak Valley, Assam, India, from March 2015 to February 2016. Factors such as age, preoperative albumin, body mass index, haemoglobin, post-operative pulmonary complication, diabetes mellitus, duration of surgery, time of presentation, intraabdominal sepsis/wound infection, raised intra-abdominal pressure, raised creatinine, ascites and malignancy were observed and analysed with odds ratio and $P$ value.
\end{abstract}

\section{RESULTS AND CONCLUSION}

Risk factors for abdominal wound dehiscence identified in this study include anaemia, hypoalbuminemia, post-operative pulmonary complications, increased intra-abdominal pressure, intra-abdominal sepsis/wound infection, delayed presentation and malignancy.

\section{KEYWORDS}

Wound Dehiscence, Hypoalbuminemia, Wound Infection, Intra-Abdominal Pressure, Peritonitis, Anaemia.

HOW TO CITE THIS ARTICLE: Talukdar M, Gopalarathnam S, Paul R, et al. Clinical study on factors influencing wound dehiscence in emergency exploratory laparotomy. J. Evolution Med. Dent. Sci. 2016;5(34):1934-1938, DOI: 10.14260/jemds/2016/457

\section{INTRODUCTION \\ The fundamental task of surgery is the management of wound. Any surgical intervention will result in a wound. The tribute for a surgeon comes from the efforts made to reduce the adverse effects of wound, remove or repair damaged tissues and gain momentum in the process of wound healing to restore function. \\ Wound healing is a mechanism wherein the body tries to re-establish the integrity of the injured part. Wound healing requires energy and is an anabolic process. Surgical incisions trigger the healing process, which is never a simple step. Rather it is a complex, chronic, continuous process with four different stages: Haemostasis, inflammation, proliferation and maturation. ${ }^{1}$ If the fortifying factors fail before the regain of functional and anatomical integrity, the wound breaks apart.}

Financial or Other, Competing Interest: None.

Submission 28-03-2016, Peer Review 09-04-2016,

Acceptance 12-04-2016, Published 28-04-2016.

Corresponding Author:

Dr. Sankamithra Gopalarathnam,

Room No. 30, Old PG Hostel,

Silchar Medical College,

Silchar, Ghungoor Outpost,

Cachar-788014, Assam.

E-mail: sankamithrag@gmail.com

DOI: $10.14260 /$ jemds $/ 2016 / 457$
Wound dehiscence etches profound morbidity in a patient's life. There arises an expanding demand in the cost of care both in terms of increased hospital stay and manpower in nursing and managing of burst wound and its complications.

The purpose of the study is to investigate the events and factors contributing to wound dehiscence in midline emergency exploratory laparotomy and to analyse their significance.

\section{MATERIALS AND METHODS}

Two hundred and thirteen patients who underwent midline emergency exploratory laparotomy were considered in the study with informed consent. Patients from 16 years to 70 years irrespective of sex were included in the study. The study was conducted in Silchar Medical College and Hospital located in Barak Valley, Assam, India, from March 2015 to February 2016 for a duration of 12 months. Ethical committee clearance was obtained. Factors such as age, hypoalbuminemia, anaemia, BMI, intra-abdominal sepsis/wound infection, IntraAbdominal Pressure (IAP), diabetes mellitus, ascites, malignancy, serum creatinine, post-operative pulmonary complications, duration of surgery and time of presentation since onset of symptoms were analysed. 


\section{The Risk Factors were framed as follows:}

1. Age more than 50 years.

2. Body mass index more than 30 (obesity). ${ }^{2}$ was considered as risk factor.

3. Pus in the abdominal cavity or from wound was noted as intra-abdominal sepsis/wound infection. Pus was sent for culture and sensitivity and antibiotics changed accordingly.

4. History of diabetes mellitus and newly diagnosed cases were included in the diabetes mellitus category and glycaemic control was achieved with physician's opinion.

5. History of COPD, cough, dyspnoea, low oxygen saturation, chest crepitations, crackles, pleural effusion were considered for post-operative pulmonary complications.

6. Patients who presented to emergency department after 48 hours of onset of symptoms were considered as delayed presentation.

7. We considered duration of surgery more than 120 minutes as prolonged surgery.

8. Malignancy was confirmed with histopathological report.

9. Intra-abdominal pressure was recorded by using bladder pressure obtained by instilling $50 \mathrm{~mL}$ of water through Foley's catheter and reading noted over graduated manometer.

10. Patients with haemoglobin less than $10 \mathrm{~g} / \mathrm{dL}$ were considered in anaemic group.

11. Patients with serum albumin less than $3.5 \mathrm{~g} / \mathrm{dL}$ were included in hypoalbuminemia group.

12. Serum creatinine more than $2 \mathrm{mg} / \mathrm{dL}$ was considered as risk factor in our study.

13. Ascites was detected by clinical and radiological methods.

All the risk factors were made measureable on the basis of history, examination and laboratory investigation. For all the patients, closure of midline laparotomy wound was done with non-absorbable No. 1 suture (Polypropylene) in continuous single layer fashion with $1 \mathrm{~cm}$ interval. Patients were closely observed post-operatively for minimum of 10 days. Special attention was given to maintain asepsis.

Broad spectrum intravenous antibiotics with anaerobic coverage was started for all cases and later changed according to culture and sensitivity report. Abdominal distension and post-operative intra-abdominal pressure on day 1 and day 3 were noted. Patients who expired post-operatively before discharge from the hospital were excluded from the study. Odds ratio and $p$ value were calculated using SPSS software version 20.

\section{RESULT}

Among 213 patients who underwent midline emergency exploratory laparotomy, 27 patients developed wound dehiscence (Figure 1).

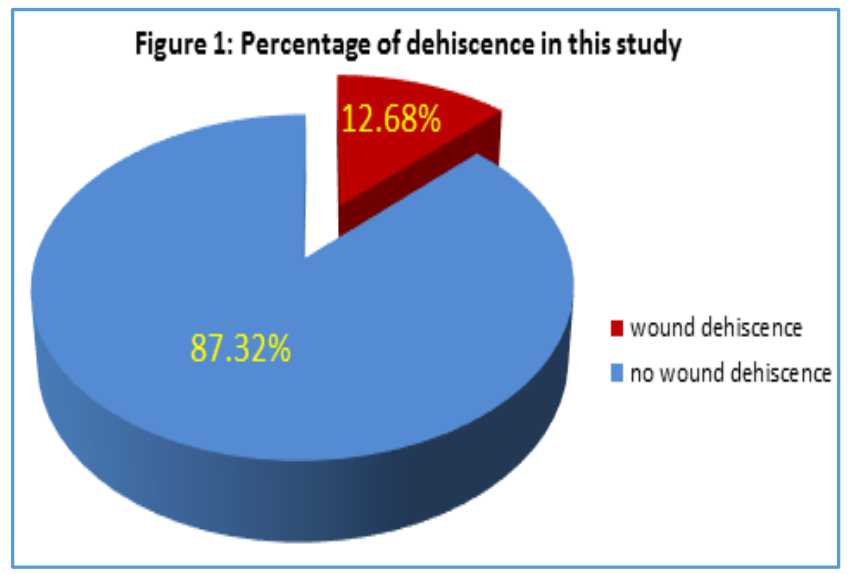

\begin{tabular}{|c|c|c|c|c|}
\hline Causes & $\begin{array}{c}\text { Non } \\
\text { Dehiscence } \\
\text { (No. of } \\
\text { Cases) }\end{array}$ & $\begin{array}{c}\text { Dehiscence } \\
\text { (No. of } \\
\text { Cases) }\end{array}$ & $\begin{array}{c}\text { Total } \\
\text { No. } \\
\text { of } \\
\text { Cases }\end{array}$ & $\begin{array}{c}\text { Percentage } \\
\text { of } \\
\text { Dehiscence } \\
\text { Cases } \\
\text { (\%) }\end{array}$ \\
\hline Obstruction & 55 & 6 & 61 & 9.83 \\
\hline Peritonitis & 91 & 21 & 112 & 18.75 \\
\hline $\begin{array}{c}\text { Blunt } \\
\text { trauma }\end{array}$ & 30 & - & 30 & - \\
\hline $\begin{array}{c}\text { Penetrating } \\
\text { trauma }\end{array}$ & 10 & - & 10 & - \\
\hline \multicolumn{2}{|c|}{ Table 1: Indications for Emergency Exploratory Laparotomy } \\
\hline
\end{tabular}

In our study, the common indication for emergency exploratory laparotomy was found to be perforation peritonitis with 112 cases out of 213 cases included in the study (Table 1). Among 112 perforation patients, 21 of them developed wound dehiscence (Figure 3). Intestinal obstruction was the second cause for surgery and penetrating trauma being the least (Figure 2).

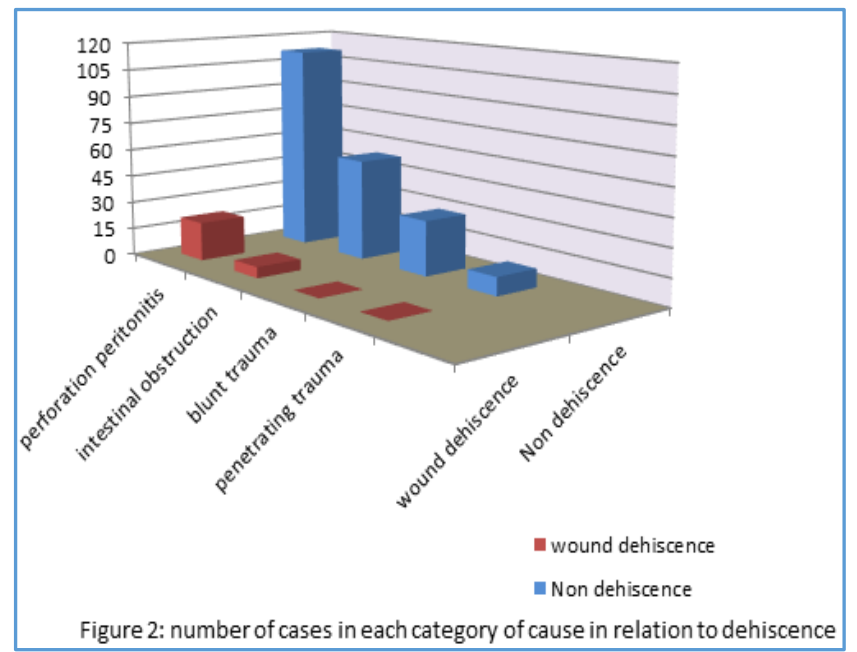




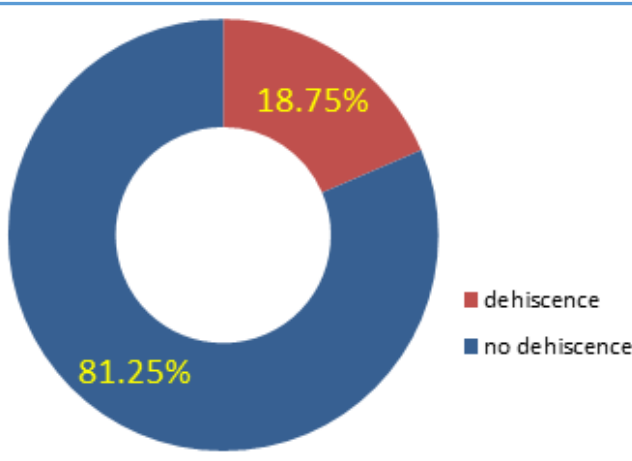

figure 3: percentage of wound dehiscence in peritonitis cases

\begin{tabular}{|c|c|c|c|c|}
\hline Factors & $\begin{array}{c}\text { Dehiscence } \\
\quad n=27\end{array}$ & $\begin{array}{c}\text { Non- } \\
\text { Dehiscence } \\
\text { n=186 }\end{array}$ & $\begin{array}{l}\text { Odds } \\
\text { Ratio }\end{array}$ & $\begin{array}{c}P \\
\text { Value }\end{array}$ \\
\hline Age $>50$ & 9 & 71 & 0.810 & 0.09 \\
\hline $\begin{array}{c}\text { Pre-operative } \\
\text { Hypoalbuminemia } \\
<3.5 \mathrm{~g} / \mathrm{dL}\end{array}$ & 24 & 61 & 16.39 & 0.000 \\
\hline $\begin{array}{c}\text { Pre-operative } \\
\text { anaemia }<10 \mathrm{~g} / \mathrm{dL}\end{array}$ & 22 & 78 & 6.09 & 0.000 \\
\hline Diabetes Mellitus & 5 & 21 & 1.786 & 0.284 \\
\hline $\begin{array}{c}\text { Body Mass Index } \\
>30\end{array}$ & 3 & 9 & 2.45 & 0.187 \\
\hline $\begin{array}{c}\text { Pulmonary } \\
\text { complications }\end{array}$ & 24 & 87 & 9.103 & 0.000 \\
\hline $\begin{array}{l}\text { Increased Intra- } \\
\text { abdominal } \\
\text { pressure on post- } \\
\text { op day } 1 \text { and } 3 \\
\end{array}$ & 21 & 18 & 32.66 & 0.000 \\
\hline $\begin{array}{c}\text { Time of } \\
\text { presentation }>48 \\
\text { hours }\end{array}$ & 18 & 41 & 7.07 & 0.000 \\
\hline $\begin{array}{c}\text { Duration of } \\
\text { surgery }>2 \text { hours }\end{array}$ & 10 & 97 & 0.534 & 0.135 \\
\hline $\begin{array}{l}\text { Intra-abdominal } \\
\text { sepsis/infection }\end{array}$ & 21 & 14 & 43.00 & 0.000 \\
\hline Ascites & 3 & 7 & 3.196 & 0.09 \\
\hline Malignancy & 3 & 2 & 11.50 & 0.001 \\
\hline $\begin{array}{l}\text { Serum Creatinine } \\
>2 \mathrm{mg} / \mathrm{dL}\end{array}$ & 6 & 27 & 1.683 & 0.301 \\
\hline
\end{tabular}

By calculating the odds ratio, patients with raised intraabdominal pressure and sepsis were found to be at more than 30 times higher risk to develop wound dehiscence. Hypoalbuminemia increases the risk for dehiscence by 16 times with significant $p$ value (Table 2). Each of them who developed wound dehiscence had a combination of minimum of 4 factors mentioned above. In dehiscence group, 33.3\% of patients belonged to age group more than 50 with no significant $\mathrm{p}$ value. More than $80 \%$ of patients had hypoalbuminemia, anaemia and pulmonary infection. Increased abdominal pressure, abdominal sepsis or wound infection were found in more than $75 \%$ of dehiscence patients with significant $p$ value. Combination of these factors put the patients at higher risk for developing wound dehiscence.

\section{DISCUSSION}

Acute wound failure addressed by various names like wound dehiscence, disruption, burst abdomen is a multifactorial problem. The understanding of wound healing and dehiscence are complicated considerably by the fact that it is uncommon for any factor to exist in isolation and to determine which factor is of greatest importance in a particular case becomes a difficult task indeed. ${ }^{3}$

The wound dehiscence rate reported in international literature varies from $1 \%$ to $2.6 \%{ }^{4}$ in observation made by Penninckx et al, dehiscence rate was found to be $6.7 \% .5$ in emergency laparotomy. While local studies show a higher incidence varying from $6 \% .6,7$ to $12 \%$. In study by Pandey S et al, overall incidence of wound dehiscence was $11.5 \%$ and $17 \%$ in patients in whom mass closure was done with Vicryl. ${ }^{8}$ In current study $12.6 \%$ of patients developed wound dehiscence which co-relates with many of Asian studies. Moreover, the higher incidence may be because the study included only emergency cases.

Likewise, study conducted by Halasz et $\mathrm{al}^{9}$, this study also shows that increase in age is not a major contributing factor for wound dehiscence. But Hanif et al ${ }^{5}$ and Makela ${ }^{10}$ et al found increased age more than 50 as a risk factor for wound dehiscence.

Hypoalbuminemia is associated with poor tissue healing, decreased collagen synthesis. ${ }^{11,12}$ in the surgical wounds or at the anastomosis site. It hampers the immune responses, such as macrophage activation and granuloma formation. Therefore, in hypoalbuminemic patients, wound infection, remote infections such as pneumonia, septicaemia and anastomotic leakage are commonly found. ${ }^{13}$ Hypoproteinemia extends the inflammatory phase and impairs fibroplasia, proliferation, proteoglycan and collagen synthesis. It decelerates neoangiogenesis and wound remodeling. ${ }^{14}$ In this study, patients with hypoalbuminemia were found to have 16 times higher chance to develop dehiscence when compared to patients with normal albumin level. Like many other studies in literature, this study also obtained a result that hypoalbuminemia has significant effect (p-value $<0.05)$ on wound dehiscence.

Anaemia is frequently blamed as an important factor in poor wound healing. But on analysing the literature, there are conflicting results among many studies. Few studies are in favour of anaemia as a causative factor in poor healing. Guiney et al found that $50 \%$ of their patients who had wound disruption were anemic. ${ }^{15}$ In contrast Marsh.16, Mann, Alexander and their colleagues found that anaemia, uncomplicated by other deficiencies did not contribute significantly to wound dehiscence. Heughan $\mathrm{C}$ et al ${ }^{17}$, did an extensive study and concluded that healing is impaired by conditions associated with anaemia such as malnutrition, low circulating blood volume and increased blood viscosity following trauma. But mild or moderate normovolemic anaemia with otherwise normal parameter is of no consequence in wound dehiscence.

In this study, intra-abdominal sepsis and wound infection hold the highest risk out of all variables for developing wound dehiscence. This result goes in favour of many studies mentioned in literature. ${ }^{18}$ Collagenase released by bacteria hampers the collagen deposition at wound site. ${ }^{19}$ Continued presence of bacteria causes influx and activation of neutrophils, thus lifting the level of degradative matrix metalloproteinases (MMPs). Insufficient tissue inhibitors of MMPs lead to wound degradation. ${ }^{20}$

In our study, patients with increased intra-abdominal pressure were found to be at 32 times higher risk to develop wound dehiscence. Tissues should have an adequate breaking strength for the sutures to hold the wound together. Increased 
intra-abdominal pressure and inflammatory mediators lowers the tissue breaking strength and increases the propensity for dehiscence. ${ }^{21}$

Moreover patients with pulmonary complications strain during cough contributing to dehiscence by increasing abdominal pressure. The increase in intra-abdominal pressure because of nausea, vomiting or cough results in breakage of suture, undoing of knots or pulling through the tissue. Fascial layers tend to lengthen as the wound distends, whereas suture length remains the same leading to breakage of suture, undoing of knot or pulling through tissue. ${ }^{22}$

Physiological stressors like infection and injury increases the metabolic rate. If this state of stress prolongs along with decrease of body mass as in malignancy, catabolic process persists. This catabolic process is mediated by glucocorticoids, catecholamines, cytokines, insulin and insulin like growth factors. Tumour burden and tissue injury cause detrimental effect on wound healing. ${ }^{23}$ In our study also, the hypothesis that malignancy serves as a risk factor for wound dehiscence is proved right with significant $p$ value.

In this study age, obesity, ascites, duration of surgery and altered renal function were not found to have significant effect in predicting wound dehiscence.

The high incidence of dehiscence with peritonitis is also reported in other studies. ${ }^{24}$ In this study, the fact that patients with peritonitis are at higher risk for wound dehiscence is strengthened.

Delayed presentation to hospital is found to have a significant p-value in this study. Delayed presentation has worsening influence over homeostasis. It leads to septicaemia, pulmonary complications, increased catabolism and altered fluid and electrolyte balance. In North Eastern part of India where this study was conducted, the probable reasons for delayed presentation are lack of awareness about diseases, difficult transportation, poverty and mismanagement by Quacks.

In the evolution of medicine, with this and similar studies a risk score for abdominal wound dehiscence can be framed into a formula to calculate the probability of developing abdominal wound dehiscence for individual patients. Thus, patients with high risk score can be included in future intervention studies that may involve preventive wound closing with reinforcements as (Biologic) mesh.

Factors like age, BMI, duration of surgery, ascites, raised serum creatinine level and diabetes mellitus were found to have insignificant $\mathrm{p}$ value.

\section{ABBREVIATIONS}

IAP- Intra-Abdominal Pressure, BMI- Body Mass Index, MMPMatrix Metalloproteinases.

\section{CONCLUSION}

In conclusion, various putative risk factors for abdominal wound dehiscence were investigated. Important risk factors for abdominal wound dehiscence identified in this study include chronic pulmonary disease, hypoalbuminemia, anaemia, malignancy, increased intra-abdominal pressure, intra-abdominal sepsis, delayed presentation and wound infection. Furthermore, utmost efforts should be made to consider minimally invasive surgery. From the results of this study, we can also conclude that a number of risk factors for abdominal wound dehiscence can be mitigated during the perioperative period. This implies that the risk of developing abdominal wound dehiscence can be reduced by preventing wound infection and by applying optimal surgical technique in every patient.

\section{REFERENCES}

1. Chin G, Diegelman R, Schultz G. Cellular and molecular regulation of wound healing. In: Falabella A, Kirschner R, ed. Wound healing. Boca Roton FL, Taylor, Francis Group 2005;17-37.

2. WHO expert consultation. Appropriate body-mass index for Asian populations and its implications for policy and intervention strategies. The Lancet 2004;363(9403):157-63.

3. Reiter D. Methods and materials for wound mangement. Otolaryngol Head Neck Surg 1994;110(6):550-6.

4. Adrian S, Peter L. Wound dehiscence, incisional hernia and para-stomal hernia. In: Moris PJ, William W, eds: Oxford textbook of surgery. Oxford University Press 2000;22nd edn:1983-90.

5. Penninckx FM, Poelmans SV, Kerremens RP, et al. Abdominal wound dehiscence in gastroenterological surgery. Ann Surg 1979;189(3):345-52.

6. Hanif N, Ijaz A, Niazi UF, et al. Acute wound failure in emergency and elective laparotomies. J Coll Physicians Surg Pak 2000;11:23-6.

7. Waqar SH, Malik ZI, Razzaq A, et al. Frequency and risk factors for wound dehiscence/burst abdomen in midline laparotomies. J Ayub Med Coll Abbottabad 2005;17(4):70-3.

8. Pandey S, Singh $M$, Singh K, et al. A prospective randomized study comparing non-absorbable polypropylene (prolene $®$ ) and delayed absorbable polyglactin 910 (vicryl $囚$ ) suture material in mass closure of vertical laparotomy wounds. The Indian Journal of Surgery 2013;75(4):306-10. doi:10.1007/s12262-012-0492-x.

9. Halasz NA. Dehiscence of laparotomy wounds. Amer J Surg 1968;116:210-4

10. Makela JT, Kiviniemi H, Juvonen T. Factors influencing wound healing after midline laparotomy. Am Surg 1995;170(4):387-9.

11. Haukipuro K, Melkko J. Connective tissue response to major surgery and postoperative infection. Eur J Clin Invest 1992;22(5):333-40.

12. Windsor JA, Knight GS, Hill GL. Wound healing response in surgical patient: recent food intake is more important than nutritional status. Br J Surg 1988;75(2):135-7.

13. Gibbs J, Cull W, Henderson W, et al. Preoperative serum albumin level as a predictor of operative mortality and morbidity: results from the national VA surgical risk study. Arch Surg 1999;134(1):36-42.

14. Pollack SV. Wound healing: a review III. Nutritional factors affecting wound healing. J Dermatology Surg Oncol 1979;5(8):615-9.

15. Guiney EJ, Morris PJ, Donaldson GA. Wound Dehiscene. A continuing problem in abdominal surgery. Arch Surg 1966;92(1):47-51.

16. Marsh RC, Coxe JW, Ross WL, et al. Factors involved in wound dehiscence. survey of 1000 cases. JAMA 1954;155(14):1197-200. 
17. Heughan C, Grislis G, Hunt TK. The effect of anaemia on wound healing. Ann Surg 1974;179(2):163-7.

18. Riou JP, Cohen JR, Johnson H. Factors influencing wound dehiscence. Am J Surg 1992;163(3):324-30.

19. Broughton G, Janis JE, Attinger CE. Wound healing: an overview. Plast Reconstr Surg 2006;177(7):1e-S-32e-S.

20. Menke NB, Ward KR, Witten TM, et al. Impaired wound healing. Clin Dermatol 2007;25(1):19-25.

21. Dubay DA, Franz MG. Acute wound healing: the biology of acute wound failure. Surg Clin North Am 2003;83(3):463-81.
22. Jenkins TPN. The burst abdominal wound: a mechanical approach. Surg 1976;63(11):873-6.

23. Wong PW, Enriquez A, Barrera R. Nutritional support in critically ill patients with cancer. Crit Care Clin 2001;17(3):743-67.

24. McGinn FP. Effects of hemorrhage upon surgical operations. Br J Surg 1976;63(10):742-6. 